Journal of Psychology. Special Pedagogy. Social Work (PSPSW) e-ISSN: 1857-4432, p-ISSN: 1857-0224, Volume 62, Issue 1, 2021, DOI 10.46728( http://psihologie.upsc.md) Psychology and Special Education Faculty “Ion Creangă”" State Pedagogical University from Chișinău

\title{
ОБЕСПЕЧЕНИЕ ИНТЕГРАЦИИ ПРОФЕССИОНАЛЬНЫХ ДИСЦИПЛИН В ПРОЦЕСС ПОДГОТОВКИ БУДУЩИХ УЧИТЕЛЕЙ НАЧАЛЬНОЙ ШКОЛЫ К ОРГАНИЗАЦИИ ТРУДОВОГО ОБУЧЕНИЯ УЧАЩИХСЯ
}

ENSURING THE INTEGRATION OF PROFESSIONAL DISCIPLINES IN THE PROCESS OF PREPARING FUTURE PRIMARY SCHOOL TEACHERS FOR THE ORGANIZATION OF LABOR TRAINING OF STUDENTS

\section{ASIGURAREA INTEGRĂRII DISCIPLINELOR PROFESIONALE ÎN PROCESUL DE PREGĂTIRE A VIITORILOR ÎNVĂȚĂTORI ÎN VEDEREA ORGANIZĂRII INSTRUIRII PRIN MUNCĂ A ELEVILOR}

B. A. Балакирева, кандидат педагогических наук, доцент, заведующая кафедры педагогических технологий начального образования Государственного учреждения «Южноукраинский национальный педагогический университет имени К. Д. Ушинского»,

Одесса, Украина

\section{CZU: 371.124/.13}

Резюме

Статья посвящена обоснованию важности обеспечения интеграции профессиональных дисциплин как одного из условий эффективной подготовки будущих учителей начальной школы к организации трудового обучения учащихся. В статье на основе анализа научной литературы раскрыта сущность понятий «интеграция», «интеграция образования», «интегративный подход». Описан интегративный подход в преподавании таких учебных дисциплин, как «История украинской культуры», «Психология общая и возрастная», «Педагогика», «Методика преподавания литературной образовательной отрасли», «Методика преподавания математической образовательной отрасли», «Методика преподавания естествоведческой образовательной отрасли», «Методика преподавания информатической образовательной отрасли», «Методика преподавания художественной образовательной отрасли», занятия которых было дополнено теоретическими знаниями и упражнениями, способствующими приобретению студентами необходимых умений, развитию профессиональных и личностных качеств, необходимых для организации трудового обучения учащихся начальной школы и внедрению указанного подхода в дальнейшую профессиональную деятельность.

Ключевые слова: будущие учителя начальной школы, профессионально-педагогическая подготовка, трудовое обучение, интеграция, интегративный подход.

\section{Abstract}

The article is devoted to the substantiation of the importance of ensuring the integration of professional disciplines as one of the conditions for the effective preparation of future primary school teachers for the organization of labor training for students. Based on the analysis of scientific literature, the article reveals the essence of the concepts of "integration", "integration of education", "integrative approach". An integrative approach in teaching such academic disciplines as "History of Ukrainian culture", "General and age psychology", "Pedagogy", "Methods of teaching the literary educational branch", "Methods of teaching the mathematical educational branch", "Methods of teaching natural science educational branch", "Methods of teaching the information educational branch", "Methods of teaching the art educational branch", the classes of which were supplemented with theoretical knowledge and exercises that contribute to the acquisition of the necessary skills by students, the development of professional and personal qualities necessary for organizing labor training of primary school students and the implementation of this approach in further professional activities.

Key words: future primary school teachers, vocational and pedagogical training, labor training, 
integration, integrative approach.

\section{Rezumat}

În acest articol se fundamentează importanța integrării disciplinelor profesionale în procesul de pregătire eficientă a viitorilor învăţători în vederea organizării instruirii prin muncă a elevilor. În baza analizei literaturii de specialitate sunt descrise noțiunile de ,integrare”, ,integrarea instruirii”. Este descrisă abordarea integrativă în predarea următoarelor cursuri: „Istoria culturii ucrainene”, „Psihologia generală și a vârstelor”, „Pedagogia”, „Metodica predării matematicii”, „Metodica predării informaticii” ș.a. Orele respective au fost completate cu materie teoretică, exerciții practice care contribuie la formarea priceperilor, dezvoltarea calităților profesionale și de personalitate necesare pentru organizarea procesului de instruire prin muncă a elevilor din ciclul primar.

Cuvinte cheie: viitorii învăţători în clasele primare, integrare, instruirea prin muncă, aspect integrativ, pregătirea profesională-pedagogică.

Новые социально-экономические и политические отношения в Украине актуализировали реформирование системы образования, мотивируя, в частности, актуальность переосмысления требований к организации образовательного процесса в начальной школе. В профессиональной деятельности учитель должен обязательно соблюдать творческий подход, поскольку в стране трансформировалось представление о роли творческого учителя в организации образовательного процесса.

Общественная потребность в инициативных, всесторонне образованных специалистах вызывает поиски нового содержания и форм организации производительного труда младших школьников. Современные тенденции развития национальной системы образования требуют теоретического обоснования и практического обновления содержания и методики профессиональной подготовки учителя, работающего с детьми. Получая образование в педагогических УВО, будущий учитель начальных классов должен быть подготовленным к реализации продуктивно-трудовой деятельности младших школьников, овладев эффективными подходами, методами, технологиями и методиками обучения.

Научного обоснования организация трудового обучения получила в ряде исследований ученых (Б. Бухалова, В. Казакевича, К. Катханова, В. Корольский, В. Мадзигона, М. Пальянова, В. Полякова, В. Симоненко, М. Скаткина, Д. Тхоржевского, И. Чернышенко, Л. Шило и др.). Особенности общепедагогической подготовки учителя исследуют А. Дубасенюк, М. Евтух, Л. Коваль, А. Кузьминский, И. Пальшкова, А. Савченко, Л. Хомич и др. В области педагогики начальной школы фундаментальное значение имеют работы Н. Бибик, Е. Биды, А. Богуш, В. Бондаря, М. Вашуленко, А. Савченко, М. Скаткина, Л. Хомич, А. Цымбалару, И. Шапошниковой и др. Проблемы 
Journal of Psychology. Special Pedagogy. Social Work (PSPSW) e-ISSN: 1857-4432, p-ISSN: 1857-0224, Volume 62, Issue 1, 2021, DOI 10.46728( http://psihologie.upsc.md) Psychology and Special Education Faculty “Ion Creangă” State Pedagogical University from Chișinău

интеграции обучения разрабатывали такие педагоги-ученые, как Н. Бибик, М. Иванчук, В. Пилипчук, А. Рудницкая, В. Тименко и др.

Целью статьи является обоснование важности обеспечения интеграции профессиональных дисциплин как одного из условий эффективной подготовки будущих учителей начальной школы к организации трудового обучения учащихся.

Одним из ведущих в подготовке будущих учителей начальной школы к организации трудового обучения учащихся является интегративный подход, который «ведет к интеграции содержания образования, то есть к целесообразному объединению его элементов в целостность, благодаря которому результаты обучения могут приобрести целостность знаний разных уровней - целостность знаний о действительности, природе той или иной образовательной отрасли, предмета, курса, раздела, темы» [5, с. 356].

По справочным источникам дефиниция «интеграция» (от лат. Integration восстановление, возобновление и integer - целый) трактуется как: «акт или процесс объединения двух или более частей таким образом, чтобы они функционировали вместе» $[17$, с. 675$]$, «объединение чего-либо в единое целое» [15, с. 237], «состояние связности отдельных дифференцированных частей и функций системы, организма в целое, так и процесс, ведущий к такому состоянию» [12, с. 229], «объединение в целое каких-либо отдельных частей; объединение и координация действий различных частей целостной системы; процесс упорядочения, согласования и объединения структур и функций в целом организме» [4, с. 500]. Интеграция, по мнению А. Бабенко, является процессом объединения, взаимопроникновения или состоянием восстановления, пополнения, восстановления в целое ранее изолированных частей (обозначает результат интеграции или действие, которое ведет к этому результату) [1, с. 9].

Рассматривая сущность интегрированных форм обучения в системе подготовки будущих учителей начальных классов к организации художественно-технологического творчества учащихся, Н. Колесник отмечает, что интеграция - это процесс взаимопроникновения наук, в результате которого основные компоненты смежных дисциплин синтезируются в целостную систему, то есть объединяются знания и умения различных отраслей наук в единую целостную картину мира. Чтобы решить подобную проблему, следует использовать интеграцию различных учебных предметов. Для этого, отмечает автор, необходимо четко понимать и осознать, что интегрировать и как это делать [7]. 
Journal of Psychology. Special Pedagogy. Social Work (PSPSW) e-ISSN: 1857-4432, p-ISSN: 1857-0224, Volume 62, Issue 1, 2021, DOI 10.46728( http://psihologie.upsc.md) Psychology and Special Education Faculty “Ion Creangă” State Pedagogical University from Chișinău

При этом отмечается, что интеграционные процессы осуществляются как в рамках уже созданной системы, что приводит к повышению уровня ее целостности и организованности, так и при возникновении новой системы с ранее не связанных элементов. Отдельные части интегрированного целого могут иметь разную степень автономии. Во время интеграции увеличивается объем и интенсивность взаимосвязей между составляющими ее системы, в частности, надстраиваются новые уровни управления. Результатом интеграции есть определенная степень интегрированности - состояние упорядоченного функционирования частей целого [16, с. 210].

Интеграцию как принцип обучения характеризует В. Радкина, которая отмечает, что интеграция базируется на гармоничном объединении знаний на основе общности научного содержания, предмета, объекта, целей преподавания и сходства научных понятий и терминов [13, с. 61]. Такие ученые, как Н. Андриив и Н. Падун, отмечают, что в общенаучном аспекте интеграция - это процесс взаимопроникновения структурных элементов различных отраслей обучения, который сопровождается обобщением и комплексностью знаний $[11$, с. 79]. По мнению И. Беха, «воплощение интеграции как дидактического принципа в учебных предметах заключается в форме их объединения и представления единым целым» [2, с. 5].

Понятие «интеграция обучения» толкуется как «отбор и объединение учебного материала по различным предметам с целью целостного, системного и разностороннего изучения важных сквозных тем (тематическая интеграция); создание интегрированного содержания обучения - предметов, которые объединяли в единое целое значения с различных отраслей» [8, с. 16]. При этом ученые (Н. Андриив, С. Мельничук, С. Омельяненко, Н. Падун, В. Радкин, А. Радул и др.) выделяют тематическую и полную интеграции: тематическая интеграция - осуществление отбора и объединения учебного материала различных предметов для целостного и всестороннего изучения важных сквозных тем; полная интеграция - создание интегрированных курсов на основе объединения в единое целое знаний по различным предметам [3, с. 36].

Следует отметить, что Концепцией Новой украинской школы предложено внедрение интегрированного и проектного обучения. Интеграция содержания обучения это ведущий принцип образования Финляндии, реализация которого начинается еще в дошкольном образовании. Таким образом это способствует тому, что учащиеся получают целостное представление о мире - ведь они изучают явления с позиции различных наук и 
Journal of Psychology. Special Pedagogy. Social Work (PSPSW) e-ISSN: 1857-4432, p-ISSN: 1857-0224, Volume 62, Issue 1, 2021, DOI 10.46728( http://psihologie.upsc.md) Psychology and Special Education Faculty “Ion Creangă” State Pedagogical University from Chișinău

учатся решать реальные проблемы с помощью знаний из разных дисциплин. Указанное свидетельствует о необходимости построения образовательного процесса на основе интегративного подхода. Рассмотрим его сущность.

Интегративный подход, по мнению В. Смирновой, предполагает умение комплексного применения знаний, их синтеза, когда перенос идей и методов из одной науки в другую лежит в основе творческого подхода к научной, инженерной, художественной деятельности человека в современных условиях научно-технического прогресса $[14$, с. 8$]$.

Полностью согласны с утверждением, что интегративный подход в подготовке будущих учителей способствует целостности знаний разных уровней - целостность знаний о действительности; о природе; с той или иной образовательной отрасли; предмета, курса, раздела, темы. Интегративный подход реализуется при изучении интегрированных курсов или отдельных предметов, когда целостность знаний формируется благодаря их интеграции на основе общих для всех предметов понятий, применению методов и форм обучения, контроля и коррекции знаний учащихся, которые направляют образовательный процесс на объект единения знаний [5, с. 356].

По А. Олейник, интегративный подход обеспечивает концептуальные связи между различными отраслями знаний, их внутреннее взаимодействие и взаимопроникновение, что способствует усилению информационного содержания и эмоциональному обогащению восприятия и мышления студентов благодаря получению дополнительного материала, дает возможность с разных сторон познать явление, понятие, достичь целостности знаний [10, с. 40]. Учёная рассматривает интеграцию содержания художественных и технологических дисциплин, что близко нашему исследованию, и, по нашему мнению, выступает основой подготовленности будущих учителей начальной школы к организации трудового обучения учащихся.

Аналогичное мнение высказывает К. Оглоблин, подчеркивая, что значительная роль в оптимизации образовательного процесса педагогов имеет интеграция естественнонаучных, гуманитарных, общепрофессиональных, прикладных знаний и инновационных специальных курсов, способствующих развитию теоретического мышления студентов, формированию у них способности к целостному системному виденью учебного материала, умению анализировать, сравнивать и обобщать [9, с. 4].

В аспекте исследования считаем, что в образовательном процессе подготовки 
Journal of Psychology. Special Pedagogy. Social Work (PSPSW) e-ISSN: 1857-4432, p-ISSN: 1857-0224, Volume 62, Issue 1, 2021, DOI 10.46728( http://psihologie.upsc.md) Psychology and Special Education Faculty “Ion Creangă” State Pedagogical University from Chișinău

будущих учителей начальной школы важное значение приобретает использование интегративного подхода, что обеспечит интеграцию знаний различных учебных дисциплин и будет способствовать формированию у студентов интереса и потребности в организации трудового обучения младших школьников; выработке ценностного отношения к результатам трудовой деятельности; направленности на трудовое обучение в будущей профессиональной деятельности, полному усвоению студентами знаний о видах и продуктах трудового обучения учащихся в начальной школе, использовании технологий трудового обучения, развитии организационных умений, умений эмоциональной саморегуляции, творческого потенциала, рефлексивных, аналитических и оценочных умений, обеспечит их подготовку к организации трудового обучения младших школьников в учебное и внеучебное время.

Учебной дисциплиной, главной целью которой выступает подготовка будущих учителей начальной школы к организации трудового обучения учащихся является «Методика преподавания технологической образовательной отрасли», однако отметим, что данная дисциплина преподается на 1 курсе, на изучение которой отведено лишь 3 кредита (90 часов) и этого слишком мало для того, чтобы действительно подготовить студентов к организации трудового обучения младших школьников.

Учитывая это, считаем, что углублению знаний и умений студентов будет способствовать интегративный подход в преподавании таких учебных дисциплин, как «История украинской культуры», «Психология общая и возрастная», «Педагогика», «Методика преподавания литературной образовательной отрасли», «Методика преподавания математической образовательной отрасли», «Методика преподавания естествоведческой образовательной отрасли», «Методика преподавания информатической образовательной отрасли», «Методика преподавания художественной образовательной отрасли», содержание которых следует дополнить теоретическими знаниями и упражнениями, способствующими приобретению студентами необходимых умений, развитию профессиональных и личностных качеств, необходимых для организации трудового обучения учащихся начальной школы и внедрению указанного подхода в дальнейшую профессиональную деятельность. Имеем в виду, что студенты при организации трудового обучения смогут использовать знания из различных образовательных отраслей (математической, естествоведческой, художественной и др.), то есть обеспечатся межпредметные связи, что, по нашему мнению, будет способствовать 
Journal of Psychology. Special Pedagogy. Social Work (PSPSW) e-ISSN: 1857-4432, p-ISSN: 1857-0224, Volume 62, Issue 1, 2021, DOI 10.46728( http://psihologie.upsc.md) Psychology and Special Education Faculty “Ion Creangă”" State Pedagogical University from Chișinău

лучшему пониманию младшими школьниками окружающего мира.

Так, например, во время преподавания учебных дисциплин психологопедагогического цикла, в частности «Психология общая и возрастная», целесообразно введение темы «Эмоциональная саморегуляция и ее роль в организации уроков трудового обучения в начальной школе», что будет способствовать приобретению знаний по эмоциональной саморегуляции учителя; использование на практических занятиях метода кейс-стади обеспечит выработку у студентов культуры поведения в конфликтных ситуациях, которыми насыщена деятельность учителя начальной школы; на занятиях по дисциплине «Педагогика» предлагаем введение темы «Народная педагогика о трудовом обучение школьников», проведение дискуссий «Как мотивировать младших школьников на трудовую деятельность», семинаров «Роль уроков трудового обучения в формировании ключевых компетентностей школьников» (согласно Концепции НУШ), «Пути и средства формирования ценностного отношения младших школьников к труду», которые предусматривают коллективное обсуждение вопроса значения трудового обучения и воспитания в образовательном процессе начальной школы, а также проведение фрагментов интегрированных уроков трудового обучения, тематических дней и тому подобное.

Успешной подготовке будущих учителей к организации трудового обучения в начальной школе, на наш взгляд, будет способствовать и интеграция знаний по учебной дисциплине «История украинской культуры», тематика которой будет дополнена материалами об особенностях художественных ремесел в разных регионах Украины и их роли в национальном и нравственном воспитании младших школьников. Художественные ремесла, отмечает Н. Кардаш, имеют глубокое воспитательное воздействие на детей, поскольку они помогают восстанавливать историко-духовную память, сосредоточены на глубинах эстетического и педагогического сознания украинского этноса. В процессе ознакомления с ними учащиеся овладевают умениями изготавливать разнообразные поделки своими руками, становясь при этом создателями окружающего мира, осознают свое значение в нем [6, с. 10].

Кроме того, в подготовке будущих учителей к организации трудового обучения младших школьников значительную роль играет интеграция знаний из таких учебных дисциплин, как «Методика преподавания литературной образовательной отрасли», в частности проведение конкурсов знатоков пословиц и поговорок о труде («народ скажет как завяжет»), загадок о труде и профессии «Отгадай-ка, что будет способствовать 
Journal of Psychology. Special Pedagogy. Social Work (PSPSW) e-ISSN: 1857-4432, p-ISSN: 1857-0224, Volume 62, Issue 1, 2021, DOI 10.46728( http://psihologie.upsc.md) Psychology and Special Education Faculty “Ion Creangă” State Pedagogical University from Chișinău

приобретению студентами знаний и умений по разработке интегративных уроков украинского языка и трудового обучения. В ходе проведения занятий по дисциплине «Методика преподавания естествоведческой образовательной отрасли» можно внедрить тему «Использование природных материалов на уроках трудового обучения», а во время учебной дисциплины «Методика преподавания информатической образовательной отрасли» формировать умения студентов находить необходимые видеоматериалы для проведения виртуальных экскурсий по музеям народного творчества Украины («Народные мастера Украины»), умения разрабатывать презентации к урокам и тому подобное.

Таким образом, обеспечение интеграции психолого-педагогических и специальных дисциплин в процессе подготовки будущих учителей начальной школы к организации трудового обучения учащихся является педагогическим условием, поскольку оно будет способствовать приобретению знаний, умений, навыков, а также личностных и профессиональных качеств, определенных в структуре подготовленности студентов к осуществлению организации трудового обучения младших школьников в дальнейшей профессиональной деятельности.

\section{БИБЛИОГРАФИЯ}

1. БАБЕНКО, А. Л. Сутність і зміст понять «інтеграція» та «інтеграційне заняття». Науковий вісник Ужгородського національного університету. Серія «Педагогіка, соціальна робота». Ужгород, 2015. Вип. 37. С 9-12.

2. БЕХ, І. Д. Виховання особистості : у 2 кн. Кн. 1 : Особистісно орієнтований підхід : теоретико-технологічні засади. Київ : Либідь, 2003. 344 с.

3. БУЧКІВСЬКА, Г. В. Підготовка учителів початкових класів на засадах народного декоративно-ужиткового мистецтва: монографія / за науковою редакцію Г. В. Терещука. Хмельницький : ПП Заколодний М. І. , 2019. 420 с.

4. Великий тлумачний словник сучасної української мови (з дод., допов. та $\mathrm{CD}$ ) / Уклад. і голов. ред. В. Т. Бусел. Київ; Ірпінь : ВТФ Перун, 2009. 1736 с.

5. Енциклопедія освіти / [гол. редактор В. Г. Кремень] / Акад. пед. наук України. Київ : Юрінком Інтер, 2008. 1040 с.

6. КАРДАШ, Н. В. Підготовка майбутніх учителів обслуговуючої праці до організації самостійної роботи учнів у процесі вивчення художніх ремесел : автореф. дис... канд. пед... наук : 13.00.02. Київ, 2006. 22 с.

7. КОЛЕСНИК, Н. Є. Інтегровані форми навчання у системі підготовки майбутніх 
учителів початкових класів до організації художньо-технічної творчості учнів. URL: https://core.ac.uk/download/pdf/12082454.pdf

8. Короткий термінологічний словник з педагогіки / укладачі С. Г. Мельничук, О. С. Радул, Т. Я. Довга, С. В. Омельяненко. Кіровоград, 2004. 36 с.

9. ОГЛОБЛИН, К. А. Опережающая стратегия подготовки педагогов физической культуры на основе непрерывного здоровьеформирующего образования : автореф. дис... докт. пед. наук : 13.00.08. Санкт-Петербург, 2008. 43 с.

10. ОЛІЙНИК, О. Модель підготовки майбутніх учителів початкової школи до формування конструктивних умінь молодших школярів. Наукові записки Тернопільського національного педагогічного університету імені Володимира Гнатюка. Серія : Педагогіка. 2017. № 1. C. 37-42.

11. ПАДУН, Н. О., АНДРІЇВ, Й. Н. Особливості форм інтегрованого навчання у сучасній школі. Наукові записки Ніжинського державного університету імені М. Гоголя. Психолого-педагогічні науки. 2011. № 1. С. 79-82.

12. Педагогічний словник / за ред. М. Д. Ярмаченка. Київ : Педагогічна думка, 2001. $516 \mathrm{c}$.

13. РАДКІНА, В. Ф. Інтегративний підхід як принцип організації професійної підготовки майбутніх учителів. Вісник Житомирського державного університету імені I. Франка. 2005. № 21. С.61-64.

14. СМІРНОВА, В. О. Інтегрований підхід до структурування змісту правових знань у професійно-технічному коледжі : автореф. дис. канд. пед. наук : 13.00.04. Київ, 2009. $21 \mathrm{c}$.

15. Тлумачний словник української мови / ред.: Т. В. Ковальова, Л. П. Коврига. Харків : Синтекс, 2002. 672 с.

16. Философский энциклопедический словарь / Под ред. А. А. Ивина. Москва : Гардарики, 2006. 1072 с.

17. Oxford Advanced Learner's Dictionary of Current English / Sixth Edition ; ed. by Sally Wehmeier. Oxford : University Press, 2000. 1540 p. 